\title{
A EDUCAÇÃO PATRIMONIAL NAS COMUNIDADES DETENTORAS DOS BENS CULTURAIS
}

Wanessa Pires Lott ${ }^{1}$

\begin{abstract}
Resumo: A problematização deste artigo parte da fala de Neusa de Assis Silva, Capitã do Congado da 'Guarda de Moçambique de Nossa Senhora do Rosário e Sagrado Coração de Jesus' - também conhecida como Reinado 'Os Carolinos' - de Belo Horizonte. Sobre as agências de salvaguarda do Estado, a capitã afirma: "se eles colocarem as Irmandades como patrimônio e ajudar com alguma coisa, aí vai ser legal, agora se só falar esse nome, deixa do jeito que tá" (SILVA, 2017). A entrevista concedida a mim nos leva a indagar a questão da Educação Patrimonial no interior dos próprios detentores dos bens culturais a serem preservados. As políticas de educação visam prioritariamente a apreensão do bem cultural pela comunidade externa, com ações vinculadas às práticas educativas escolares e/ou em instituições de memória. No entanto, este estudo apresenta a necessidade dos órgãos de preservação voltarem-se também para as próprias comunidades detentoras.
\end{abstract}

Palavras-chave: Patrimônio Cultural, Educação Patrimonial, Reinado de Nossa Senhora do Rosário, Belo Horizonte.

\section{HERITAGE EDUCATION IN COMMUNITIES OWNERS CULTURAL PROPERTIES}

\begin{abstract}
The problematization of this article starts from the speech of Neusa de Assis Silva, Captain of Congado of the 'Guarda de Moçambique de Nossa Senhora do Rosário e Sagrado Coração de Jesus' - also known as Reinado 'Os Carolinos' - from Belo Horizonte. Regarding the State's safeguarding agencies, the captain says: "if they put the Brotherhoods as patrimony and help with something, then it will be cool, now if they just say that name, leave it the way it is" (SILVA, 2017). The interview given to me leads us to ask the question of Heritage Education within the holders of the cultural assets themselves to be preserved. Education policies aim primarily at the seizure of the cultural good by the external community, with actions linked to school educational practices and / or memory institutions. However, this study presents the need for preservation organs to also address the detaining communities themselves.
\end{abstract}

Key Words: Cultural Heritage, Heritage Education, Brotherhoods of Nossa Senhora do Rosário, Belo Horizonte.

\section{EDUCACIÓN PATRIMONIAL EN COMUNIDADES DETENTORAS DE BIENES CULTURALES}

Resumen: La problematización de este artículo comienza con el discurso de Neusa de Assis Silva, Capitán del Congado de la 'Guarda de Moçambique de Nossa Senhora do Rosário e

\footnotetext{
${ }^{1}$ Doutora em História pelo Programa de Pós-Graduação em História da Universidade Federal de Minas Gerais (UFMG). Professora do curso de Museologia da Universidade Federal do Pará (UFPA). E-mail: wanessalott@hotmail.com.
} 
Sagrado Coração de Jesus' también conocido como Reinado 'Os Carolinos', de Belo Horizonte. Con respecto a las agencias de protección del Estado, el capitán dice: "si ponen a las Hermandades como patrimonio y ayudan con algo, entonces será genial, ahora si solo dicen ese nombre, déjenlo como está" (SILVA, 2017). La entrevista que me dieron nos lleva a hacer la pregunta sobre la educación del patrimonio dentro de los titulares de los bienes culturales que se deben preservar. Las políticas educativas apuntan principalmente a la toma del bien cultural por parte de la comunidad externa, con acciones vinculadas a las prácticas educativas escolares y / o instituciones de memoria. Sin embargo, este estudio presenta la necesidad de que los órganos de preservación también aborden las comunidades de detención.

Palabras Clave: Patrimonio Cultural, Educación del Patrimonio, Reinado de Nossa Senhora do Rosário, Belo Horizonte.

\section{Introdução}

A trajetória da salvaguarda dos bens culturais no Brasil inicia-se com a criação do Instituto do Patrimônio Histórico Artístico Nacional (IPHAN) ${ }^{2}$ na década de 1930 com o foco no tombamento dos bens de natureza material. A partir da década de 1980, os debates em torno dos patrimônios imateriais ganham mais foco no IPHAN e a esta mudança nas políticas preservacionistas, acrescento os estudos mais efetivos em torno da educação patrimonial (e/ou educação para o patrimônio e/ou educação com o patrimônio ${ }^{3}$ ) na virada para o século XXI.

Tais estudos partem do princípio que o patrimônio cultural é uma fonte primária de conhecimento que apoia a construção da identidade cultural, podendo levar à construção de um sentimento de cidadania. Assim sendo, é relevante promover um processo permanente e sistemático de educacional patrimonial que visa o conhecimento do bem, para que haja uma efetiva apropriação e uma consequente valorização do bem cultural. No entanto, questiono como o IPHAN e agências afins trabalham a educação patrimonial nas próprias comunidades detentoras do bem cultural. Nestas, a preocupação de conhecer e apropriar não faz tanto

\footnotetext{
${ }^{2}$ IPHAN é a atual denominação do órgão preservacionista nacional. No entanto, este passou pelas seguintes denominações ao longo do tempo: SPHAN - Serviço do Patrimônio Histórico e Artístico Nacional de 1937 a 1946. DPHAN - Departamento do Patrimônio Histórico e Artístico Nacional de 1946 a 1970. IPHAN - Instituto do Patrimônio Histórico e Artístico Nacional de 1970 a 1979. SPHAN - Secretaria do Patrimônio Histórico e Artístico Nacional de 1979 a 1990. IBCP - Instituto Brasileiro do Patrimônio Cultural de 1990 a 1994. IPHAN Instituto do Patrimônio Histórico e Artístico Nacional desde 1994. (PESSÔA,1999). No entanto, opta neste texto por utilizar apenas a sigla atual, como intuito de trazer maior fluidez a este estudo.

${ }^{3}$ No Brasil o termo Educação Patrimonial foi mais difundido a partir da década de 1980. Posteriormente surgiram outros termos como Educação para o Patrimônio e Educação com o patrimônio, com intuito de problematizar os 'usos' da Educação Patrimonial (IBRAM, 2018). No entanto, neste artigo será trabalhado apenas o termo Educação Patrimonial, sem trabalhar com as nuanças dos termos.
} 
sentido, mas, como parte relevante das políticas de salvaguarda, os detentores dos bens culturais devem ter um peso nesta equação preservacionista.

Este questionamento surgiu durante minha pesquisa voltada para os Reinados de Nossa Senhora do Rosário dos Pretos em Belo Horizonte. Ouvi a seguinte fala da então presidente do Reinado os Carolinos: "se eles [as agências de preservação do Estado] colocarem as Irmandades como patrimônio e ajudar com alguma coisa, aí vai ser legal, agora se só falar esse nome, deixa do jeito que tá" (SILVA, 2017: informação oral). Esta preocupação da representante do Reinado se coloca principalmente em torno do alto custo para certas regularizações urbanas - como por exemplo, o registro das atas em cartórios e a emissão da Certidão de Baixa de Construção, documento exigido pela prefeitura da cidade após a finalização de obras nos terrenos urbanos. Mesmo que estes documentos não estejam diretamente vinculados a um possível Registro e/ou Tombamento da comunidade, estas informações acabam por provocar confusões no entendimento salvaguarda do bem cultural.

Partindo deste evento, problematizo a questão da educação patrimonial, principalmente entre os próprios detentores dos bens culturais. Ao levantar os estudos sobre o tema, percebe-se que as análises sobre as políticas de educação patrimonial visam prioritariamente a valorização do bem cultural pela comunidade externa, deixando uma lacuna nas comunidades que vivenciam cotidianamente o seu patrimônio. Assim sendo, a organização deste artigo será feita em quatro tópicos, além desta introdução e de uma consideração final. No primeiro será apresentada a localidade que me despertou para a questão da educação patrimonial voltada para a comunidade. Apesar de não ser um trabalho direcionado ao estudo do Reinado é relevante fazer um breve relato deste para a contextualização da problematização deste estudo. Em um segundo momento o debate sobre o patrimônio cultural no Brasil em sua fase heroica, que data entre 1937 e 1967. Na sequência, a ampliação do conceito de patrimônio e o questionamento sobre as formas de educação patrimonial serão demonstrados.

\section{O Reinado 'os Carolinos'}

A história dos Reinados de Nossa Senhora do Rosário dos Pretos na atual cidade de Belo Horizonte apresenta dois marcos relevantes. Ainda quando a localidade era um pequeno arraial, tem-se no Arquivo Ultramarino a referência de uma Irmandade datada de 1807 e no Arquivo Público Mineiro, identifica-se outra em 1811. Após a inauguração da nova capital de 
Minas Gerais em doze de dezembro de 1897, registra-se em atividade apenas a 'Guarda de Moçambique de Nossa Senhora do Rosário e Sagrado Coração de Jesus', também conhecida como 'Reinado os Carolinos', criada em 1917. A partir de 1933, o número de Reinados cresceu consideravelmente, chegando a quinze até o final da década de 1990. (GYBRAN e MOYSÉS, 2014).

Tradicionalmente Reinado refere-se às associações religiosas de leigos que fazem o festejo em homenagem a Nossa Senhora do Rosário dos Pretos. No entanto, esta designação apresenta similaridades com: Irmandade, congado e bantos católicos. Para esta última, a relação se dá devido às inúmeras ocorrências das coroações de Rei Congo nas "regiões que receberam maiores contingentes de africanos de etnias bantos, oriundos da África centroocidental. Nesta inserem-se os bacongos, habitantes do antigo reino do Congo". (SOUZA, 2002, p. 258) (grifo meu).

Por conseguinte, os termos congado, congada e congo também vinculam à coroação de reis e rainhas negras conguenses. No entanto, estas designações se confundem com o nome de uma das guardas que participam do festejo: a Guarda do Congo. Esta, juntamente com o Moçambique, o Catopê, os Caboclinhos (ou Caiapós) e a Marujada (ou Marujos), compõem o cortejo em homenagem à santa. João Lopes, que entre os anos de 1975 e 2004 foi Capitãomor da Irmandade de Nossa Senhora do Rosário do Jatobá, um dos mais respeitados Reinados de Belo Horizonte, nos esclarece a diferenciação dos termos:

[...] fazer congado é muito fácil, eu quero ver fazer Reinado (....) Para fazer Reinado busca o fundamento, segundo a tradição contada pelos negros velhos, que eu preservo até hoje na Reinado de Nossa Senhora do Rosário do Jatobá, daquilo que foi mostrado lá na beira mar, quando a Virgem Maria apareceu para os negros para que eles adquirissem a sua liberdade. Por isso que negro velho tem fé no Ripungo de Manganá, que significa o Rosário de Maria (LOPES, 2005: 17).

Assim sendo, os Reinados, e também chamados de Irmandades, são organizações de leigos católicos que louvam Nossa Senhora do Rosário dos Pretos por meio da organização hierárquica. Esta devoção festiva se organiza em várias guardas de dançantes e cantantes que saem em cortejo para prestar suas homenagens à santa (LOTT, 2005). Tradicionalmente, estes Reinados são constituídos por promessas de seus fundadores, mas os Carolinos surgiu apenas por um desejo pessoal de Francisco Carolino, o Chico Calu. "Ele achava bonito e por ele, meu bisavó já era escravo, então isso veio de lá pra cá” (SILVA, 2017: informação oral). Por tal motivo que o Reinado também é conhecido como 'os Carolinos' e esta duplicidade de 
designação não é um problema, pois a Irmandade "é de 1917 e tá aí até hoje, o nome não é mais importante. Importante é a nossa fé, a nossa vontade, é a nossa capacidade de sobreviver" (TIZUMBA, 2012 apud OS CAROLINOS, 2012: sem página).

A primeira sede do Reinado foi a roça de Chico Calu, localizada na divisa dos atuais municípios mineiros de Contagem e de Esmeraldas. Posteriormente, o Reinado foi transferido para Belo Horizonte e suas atividades iniciaram na antiga Vila Maria Aparecida, uma região periférica de fazendas cortada pelo córrego 'Corguinho', antigo nome da avenida sanitária que os membros do Reinado descrevem como esgoto a céu aberto. Por alguns contos de réis, o terreno foi comprado e a igrejinha em homenagem à santa foi construída em adobe. Mesmo com inúmeras destruições da igreja - devido aos desmoronamentos do barranco acima da construção - a comunidade manteve suas atividades de forma ininterrupta, dando continuidade ao Reinado (LOTT, 2017).

Desta maneira percebe-se que há uma continua valorização e apropriação do que hoje - tecnicamente/academicamente - denominamos como patrimônio cultural. A continuidade da comunidade se fundamenta, não só na tradição oral como também no mito passado de geração para geração.

O congado é uma história muito antiga que meu avô contava pra gente que veio dos escravos, né. Então quando a Nossa Senhora Apareceu no Mar, então foi aonde o Moçambique conseguiu tirar, teve várias guardas, guardas bonitas, né, igual catopé, né, um monte de guardas bonitas tentando tirar ela e não conseguiram. Então vieram os escravos, descalços, né, bem humilde, e que conseguiram tirar ela, tó resumindo a história, não dá pra contar toda não. Conseguiram tirar ela, então foi aonde formaram a guarda de Moçambique, que foram os que conseguiram tirar ela do mar. Então os senhores, dizem que eles acharam um abuso, um absurdo, aqueles pobres descalços ficarem com ela, então fizeram uma capela pra ela e pegaram ela e colocavam na capela deles. E aí no outro dia ela não tava lá. Ela tava dentro da senzala com os negros. E aí que os negros apanhavam, apanhavam que achavam que os negros que pegavam ela. E pegavam ela e levava, pegava ela de novo e levava pra capela deles. Aí no outro dia ela tava na senzala de novo. Aí pegou e desistiu, né. Desistiu de pegar ela e deixou lá com os negros. Então eu entendo assim, é daí que vem o Moçambique com adoração a ela. (AGENDA, 2016: sem página).

Com base no mito, o ciclo festivo é constituído com a abertura das homenagens feita pelo Candombe, o "pai do Reinado" que deve ser "respeitado nas Irmandades como trono superior” (DA CRUZ, apud GILBRAN e MIYSÉS 2014: 135). Depois há o levantamento do mastro com a bandeira de aviso no terreiro da comunidade. Esta prática, que ocorre meses antes da maior festa do Reinado, tem a função de materializar a abertura do congado e 
demarcar os espaços sagrados. Após o levantamento da bandeira de aviso, inicia-se a novena que termina com o levantamento da bandeira de guia. Com os mastros levantados tem-se a sequência dos encontros de oração, das promessas, das promoções para angariar dinheiro para a "festa grande"4. Também começam os preparativos de decoração e o reparo dos instrumentos musicais a ser utilizados no grande dia, trazendo, assim, a festa para o cotidiano de cada devoto.

A 'festa grande' dos Carolinos ocorre em quatro dias, sempre em uma sexta feira, um sábado, um domingo e uma segunda. O primeiro dia é reservado apenas para os membros do Reinado e os demais são abertos a todos. Na sexta pela madrugada há o levantamento da bandeira dos santos venerados, que geralmente são: Nossa Senhora do Rosário, São Benedito, Santa Efigênia e Nossa Senhora das Mercês. Na sequência, tem-se a alvorada ao som dos primeiros repiques de tambores e caixas, anunciando a coroação dos reis do congo e dos reis festeiros. Após a coroação, tem-se o cortejo formado pela a bandeira da guia, pelas guardas de Congo e de Moçambique, pelo andor com a Santa, pelo Reinado coroado e, por fim, pelos devotos (SILVA, 2017).

Esta sequência obrigatória recria o mito fundador da retirada da santa das águas pelos Moçambiques, mas que teve a abertura dos caminhos realizada pelo Congo. Nos cânticos reconta-se esta história: "Foi na beira do mar / Foi que nego chorou / Quando viu Nossa Senhora / saindo das águas cobertas de flor” (OS CAROLINOS, 2012: sem página). A guarda do Congo é fardada com fitas coloridas e dançam com o corpo ereto, voltado para o céu, enquanto os Moçambiques louvam à Nossa Senhora equipados de uma espécie de chocalho nos pés denominado de gunga e dançam descalços, olhando para o chão.

Na procissão a gente sai assim mesmo, descalço, com chapéu ou turbante, mas agora a gente vai acabar com esse chapéu. É porque na verdade escravo não usava chapéu, usava turbante. (SILVA, 2017: informação oral).

A hierarquia do cortejo é de suma relevância para o Reinado não só para o dia da 'festa grande' como no cotidiano dos congadeiros. No cortejo tem-se o reflexo deste respeito aos cargos: os mais importantes são os reis, seguidos pelas rainhas e pelas princesas. Depois estão o capitão mor, o capitão regente, o capitão da guarda de Moçambique e o capitão da guarda de Congo. Por fim, estão os caixeiros e os dançantes, estes, mesmo estando em último patamar da hierarquia, exercem uma função de reforço da fé fundamental no Reinado, pois a:

\footnotetext{
${ }^{4}$ A 'festa grande' é a designação da maior festa da comunidade, onde ocorre o cortejo em homenagem à Nossa Senhora do Rosário dos Pretos pelas ruas do bairro da sede da Irmandade.
} 
[...] dança é que nem oração. A reza pro negro congadeiro, a fé, não está só nas palavras que vem do Rosário, ou mesmo só no canto sagrado que sai de sua boca, mas está também no corpo que dança, porque corpo que dança reza. Negro dançante e rezador. (TIZUMBA, apud GILBRAN e MOIYSÉS 2014: 153) .

Seguindo com a apresentação da festa, a procissão com o translado da santa percorre as ruas da região e retorna ao terreiro, terminando com chegada à igrejinha da sede, trajeto este que se mantém desde os tempos mais remotos. O translado de saída e chegada ao mesmo ponto é assim realizado devido à distância de uma igreja católica quando o Reinado ali se instalou. A solução encontrada por Seu Calu foi a construção de uma igreja própria que, mesmo não sendo oficialmente sacralizada pela Igreja, é pelos membros do Reinado considerada sagrada.

Neste momento processional, o pagamento de promessas é feito tanto pelos membros do congado quanto pelos demais devotos de Nossa Senhora do Rosário dos Pretos, mantendo a lógica de quanto maior for o pedido maior deve ser a paga da promessa (SANCHIS, 1983). Ao chegar ao terreiro, orações e pedidos de licença são entoados nos cânticos para, enfim, iniciar o banquete oferecido pelo Reinado a todos os presentes. $\mathrm{O}$ encerramento da 'festa grande' se dá com o agradecimento e despedida dos reis festeiros e, posteriormente, com a descida das bandeiras dos mastros.

Esta configuração festiva advém de um contexto histórico português que aporta no Brasil com a colonização. Guardadas as devidas modificações decorrentes da ação do tempo e das condições sociais, o festejo se mantém bem próximo às raízes da comunidade em questão. Assim sendo, percebo que a preservação da devoção festiva a Nossa Senhora do Rosário dos Pretos é efetiva pela própria Irmandade. A possibilidade de salvaguarda pelos órgãos preservacionistas é muito mais uma forma de reconhecimento destas diante do Estado. No entanto, devido à natureza do Reinado, até mesmo este reconhecimento só seria possível após o ano de 2000, com a instituição do Registro de Bens Culturais. Esta trajetória de ampliação do conceito de patrimônio cultural e as formas de educação patrimonial serão trabalhados nos próximos tópicos deste artigo.

\section{Os primeiros passos do Patrimônio Cultural no Brasil}

Devido à relevância cultural e histórica dos Reinados de Nossa Senhora do Rosário dos Pretos no Brasil, não se faz estranhar que estas sejam alvo de um reconhecimento e 
salvaguarda por parte das agências preservacionistas ${ }^{5}$. Contudo, as possibilidades de preservação, seja no âmbito material e/ou imaterial tornam-se apenas uma parte de tal ação. Um dos pontos de extrema relevância é o trabalho da educação em torno deste patrimônio cultural.

Entende-se como educação patrimonial o processo permanente e sistemático de trabalho educacional voltado para um bem ou um conjunto de bens patrimoniais, percebendo este(s) como uma fonte conhecimento primária por meio da educação patrimonial tem-se:

[...] um processo ativo de conhecimento, apropriação e valorização de sua herança cultural, capacitando-os para um melhor usufruto destes bens, e propiciando a geração e a produção de novos conhecimentos, num processo contínuo de criação cultural (HORTA, GRUNBERG E MONTEIRO, 1999: $05)$

Partindo do pressuposto que só se preserva o que se conhece, a intrínseca relação entre conhecer e preservar foi aos poucos sendo incorporada pelo IPHAN. Na fase heroica ou período de 'pedra e cal' que data entre 1937 e 1967, três intelectuais se destacaram: Mário de Andrade, Rodrigo Melo Franco de Andrade e Aloísio Magalhães. O primeiro foi o responsável pela elaboração do anteprojeto de criação do IPHAN, que por sua vez teve forte influência de seus iniciais trabalhos nas políticas públicas como diretor do Departamento de Cultura do Município de São Paulo na década de 1930. Apesar de inicialmente ter uma visão pautada em suas experiências etnográficas pelo Brasil, o anteprojeto sofreu várias modificações que esvaziaram a abordagem antropológica de Mário de Andrade e o órgão pautou nas políticas voltadas para os bens de natureza material.

No âmbito educacional o intelectual afirmou que a constituição dos museus e dos Livros de Tombo seriam canais profícuos de proteção, difusão e promoção do patrimônio artístico nacional. Por meio da ideia de enriquecimento da cultura brasileira através da preservação de suas obras de arte, e do também enriquecimento do povo brasileiro pela promoção do conhecimento de sua cultura, Mário de Andrade vinculou a difusão e a promoção à educação. Apontou assim, a possível função educativa do patrimônio cultural por meio da relação: informar, fazer e conhecer. Assim sendo, a educação estaria inserida como

\footnotetext{
${ }^{5} \mathrm{Na}$ esfera do IEPHA/MG tem-se em julho de 2013 o registro da Festa de Nossa Senhora do Rosário dos Homens Pretos de Chapada do Norte. Em maio de 2014, a Festa de Nossa Senhora do Rosário da Comunidade dos Arturos também foi declarada patrimônio cultural imaterial de Minas Gerais. Esta comunidade é responsável pela manutenção, dentre outros bens culturais, do Congado com as Guardas de Congo e Moçambique (IEPHA/MG, 2019). No âmbito do IPHAN, o órgão está realizando o Inventário Nacional de Referências Culturais (INRC) das Congadas de Minas Gerais e dos saberes do sagrado da Irmandade do Rosário. (IPHAN, 2019).
} 
uma ferramenta de legitimação e difusão dos valores patrimoniais definidos pelo Estado (IPHAN, 2014).

Neste ponto, se faz relevante uma pausa para ressaltar as diretrizes que o IPHAN tomou em sua fase inicial. Nesta época, a 'retórica da perda' - para utilizarmos o termo de Reginaldo Gonçalves (2002) - deu o tom das políticas públicas do órgão de preservação. Diante de um discurso de detrimento do patrimônio nacional pela falta de conservação das edificações e cidades ditas históricas - melhor dizendo, com feições coloniais -, iniciou a construção de políticas nacionais voltadas para a educação. Segundo Mário de Andrade, o fator principal no processo de desaparecimento do patrimônio histórico e artístico nacional era a indiferença da população em relação ao patrimônio cultural. Indiferença, segundo ele, partilhada não apenas pelas massas pouco esclarecidas da população brasileira, mas, igualmente, pelas classes mais favorecidas e que se presumiam 'cultas ${ }^{6}$.

Neste ponto, o diagnóstico de Mário de Andrade se aproximou do discurso de Rodrigo Melo Franco de Andrade, então presidente do IPHAN. Este também propunha colaborar na tarefa de 'educar' a população a respeito dos valores representados pelo patrimônio nacional. Em um viés paternalista que permeava o país no período da fase heroica do IPHAN, o projeto pedagógico destes intelectuais pautou na capacidade do Estado educar o povo brasileiro também pelo âmbito do patrimônio cultural. No entanto, se tomarmos uma análise mais próxima dos escritos de Mário de Andrade e de Rodrigo Andrade, as diferenças são perceptíveis. Enquanto o primeiro acreditou que a difusão do patrimônio artístico nacional deveria enriquecer culturalmente o povo brasileiro, o segundo tomou a diretriz que a educação deveria colaborar diretamente na preservação do patrimônio nacional para evitar a mutilação, o desaparecimento e a perda dos monumentos nacionais. Por ser o diretor do órgão preservacionista, as tendências de Rodrigo ganharam o destaque.

A ideia central era "colecionar" monumentos para contemplação e para construção simbólica da identidade nacional como povo civilizado. Nesse sentido, colaborar na preservação dos monumentos nacionais tombados era um ato cívico. A relação de pertencimento, o sentimento de identidade ou a função memorial (...), interessava na medida em que contribuía e/ou confirmava a narrativa oficial que atribuía aos bens o título de patrimônio histórico e artístico nacionais (SIVIERO, 2015:90). (Destaque do autor).

\footnotetext{
${ }^{6} \mathrm{O}$ termo 'cultas' aparece aqui entre aspas para marcar uma designação da época em questão, a saber, a primeira metade do século XX. Posteriormente, com os avanços das ciências humanas no Brasil, este termo passa ter uma conotação pejorativa, pois entende-se que a questão da cultura está presente em todas as esferas sociais. Para maior entendimento, ver o belo texto de Roberto da Matta, "Você tem cultura?" (1981).
} 
Dentre as ações educacionais desta fase estavam a criação de museus, o incentivo às exposições e a publicação da Revista do Patrimônio. Sobre esta, iniciada em 1937, o intuito era de utilizá-la como ampla ferramenta de educação. No entanto, parece não ter sido considerado o alcance de tal medida para um país com o grande número de analfabetos e dos artigos com inúmeros termos técnicos. Em uma análise distanciada, percebe-se que a Revista foi uma publicação profícua para os intelectuais que estavam envolto da criação do atual IPHAN. Como nos lembra Rubino (1996), em uma publicação na própria Revista do Patrimônio, o IPHAN na fase de 'pedra e cal' foi um lugar de intelectuais, que por sua vez traçaram os caminhos para a educação patrimonial sob a luz das conferências internacionais.

A conferência, profundamente convencida de que a melhor garantia de conservação de monumentos e obras de arte vem do respeito e do interesse dos próprios povos, considerando que esses sentimentos podem ser grandemente favorecidos por uma ação apropriada dos poderes públicos, emite o voto de que os educadores habituem a infância e a juventude a se absterem de danificar os monumentos, quaisquer que eles sejam, e lhes façam aumentar o interesse de uma maneira geral, pela proteção dos testemunhos de toda a civilização. (ESCRITÓRIO INTERNACIONAL DOS MUSEUS SOCIEDADE DAS NAÇÕES, 1931: 04).

Sendo assim, a questão educacional seguiu um caminho mais acadêmico como pode ser identificado no texto supra citado da Carta de Atenas (1931). Tal perspectiva também pode ser observada na Carta de Nova Délhi (1956) e a Carta de Paris (1968).

\section{Ampliação do conceito de Patrimônio Cultural e suas consequências para a Educação Patrimonial}

Com a morte de Rodrigo, o Renato Soeiro assumiu a direção do órgão, dando início à fase moderna do IPHAN. Apesar dos avanços nas políticas de preservação como a descentralização das decisões e implantação do Programa Integrado de Reconstrução das Cidades Históricas (PCH), lançado em 1973, as questões da educação patrimonial continuaram na mesma perspectiva do dirigente anterior e das cartas patrimoniais internacionais, trazendo uma relação direta entre conhecer para preservar.

Com gestão de Aloísio Magalhães em 1979 e 1982 observa-se um processo de reorganização dos conceitos e das formas de operar a preservação do patrimônio no Brasil. O IPHAN se fundiu com o PCH e com o Centro Nacional de Referências Culturais (CNRC), ao mesmo tempo se dividiu em um órgão normativo - Secretaria do Patrimônio Histórico e Artístico Nacional (SPHAN) - e um órgão executivo - a Fundação Nacional Pró-Memória 
(FNPM). Conceitualmente, a mudança proposta por Magalhães voltou para a mudança do patrimônio histórico e artístico para patrimônio cultural. A ideia foi trabalhar a partir da perspectiva de referências culturais em detrimento do conceito de monumento nacional (FONSECA, 1997).

Cabe ressaltar que as referências culturais não se resumem à produção de informações e à pesquisa de suportes materiais para documentá-las, mas significa algo mais amplo: um trabalho de elaboração desses dados, de compreensão de bens e práticas realizadas por determinados grupos sociais, tendo em vista a construção de um sistema referencial da cultura daquele contexto específico (FONSECA, 1997). Sendo assim, embora não tenha atuado diretamente com projetos na área de educação, as novas diretrizes teóricas e conceituais buscaram maneiras de aproximação com o ponto de vista dos sujeitos diretamente envolvidos na dinâmica da produção, da circulação e do consumo de bens culturais. Tal medida favoreceu a instauração de parâmetros renovados para uma interlocução mais abrangente entre processos educacionais e preservação patrimonial.

Como reflexo desta nova perspectiva, houve a elaboração das "Diretrizes para operacionalização da política cultural do MEC" em 1981 e o documento para a "Interação entre educação básica e os diferentes contextos culturais existentes no país" em 1982. Estes tiveram a finalidade de desenvolver ações destinadas a proporcionar à comunidade os meios para participar em todos os níveis do processo educacional. O objetivo era garantir que a apreensão de outros conteúdos culturais fosse adquiridos a partir dos valores próprios da comunidade (SPHAN, 1982). Ademais, houve a ampliação do conceito de patrimônio cultural no Brasil, os bens culturais passaram a ser valorizados não apenas por uma suposta exemplaridade, mas por fazerem parte da vida cotidiana. Em 1988, a Constituição Federal incorporou a nova diretriz patrimonial nos artigos 215 e 216.

Constituem patrimônio cultural brasileiro os bens de natureza material e imaterial, tomados individualmente ou em conjunto, portadores de referência à identidade, à ação, à memória dos diferentes grupos formadores da sociedade brasileira, nos quais se incluem: I - as formas de expressão; II - os modos de criar, fazer e viver; III - as criações científicas, artísticas e tecnológicas; IV - as obras, objetos, documentos, edificações e demais espaços destinados às manifestações artístico-culturais; V - os conjuntos urbanos e sítios de valor histórico, paisagístico, artístico, arqueológico, paleontológico, ecológico e científico (BRASIL, 1988: art 215).

Assim, a definição do patrimônio cultural brasileiro passou a incluir as manifestações culturais como artesanato, culinária, danças, músicas, modos de vestir e falar, maneiras de 
pescar, cultivar, construir, ritos, festas religiosas e populares, relações sociais, dentre outros aspectos representativos do povo brasileiro. Neste sentido, houve a necessidade de um novo tipo de instrumento para a preservação de tais bens, passível de adotar como patrimônio os testemunhos orais, os conhecimentos, as criações e as celebrações de nossa cultura. A busca de uma forma eficaz para salvaguardar o patrimônio não consagrado deu continuidade aos estudos realizados principalmente pela equipe de Aloísio Magalhães.

Em novembro de 1997, realizou-se em Fortaleza o "Seminário de Patrimônio Imaterial: estratégias e formas de proteção", com o apoio de diversos representantes de instituições públicas, privadas e da Organização das Nações Unidas para a Educação, a Ciência e a Cultura (UNESCO). O objetivo foi recolher ideias que permitissem a elaboração de diretrizes para a criação de instrumentos legais e administrativos que visavam identificar, proteger, promover e fomentar os bens de natureza imaterial e considerá-los em toda a sua complexidade, diversidade e dinâmica (IPHAN, 1997). Como fruto dos debates do seminário criou-se em 1998 a Comissão e o Grupo de Trabalho do Patrimônio Imaterial (GTPI) para levantar as possibilidades de apoio e proteção a esses bens culturais.

Posteriormente instituiu-se o 'Registro de bens culturais de natureza imaterial' e o 'Inventário de referências culturais - INRC' através do Decreto Federal no 3.551, de 4 de agosto de 2000. A partir deste decreto, o bem inventariado tem a possibilidade ser inscrito em um dos quatro livros de Registro: Livro dos Saberes, Livro das Celebrações, Livro das Formas de Expressão e Livro dos Lugares. Assim sendo, o registro de bens culturais imateriais possibilitou o reconhecimento das memórias dos diversos grupos formadores de nossa sociedade. Houve a possibilidade de inserção de bens culturais de comunidades que até então não eram possíveis de serem representadas pelos Livros do Tombo, como o caso do Reinado de Nossa Senhora do Rosário dos Pretos, apresentado neste texto.

Na esteira deste pensamento, destaca-se em 1983 a introdução da expressão educação patrimonial como uma metodologia inspirada no modelo da heritage education, desenvolvido na Inglaterra. Em 1996, Maria de Lourdes Parreiras Horta, Evelina Grunberg e Adriana Queiroz Monteiro lançaram o 'Guia Básico de Educação Patrimonial', que se tornou o principal material de apoio para ações educativas realizadas pelo IPHAN durante o final do século XX. O guia traz os estudos de caso de ações educacionais em cinco locais: no sítio arqueológico dos remanescentes de São Miguel das Missões, no centro histórico de Antônio Prado, no espaço rural da $4^{\text {a }}$ Colônia de Imigração Italiana, todas localizadas no Sul do Brasil, no Museu Imperial de Petrópolis/RJ e na comunidade indígena Tikuna. 
Além da apresentação das referidas experiências, a publicação também discute o termo educação patrimonial, destacando a relevância da diversidade cultural, da importância do passado e da percepção do patrimônio como dinâmico e vivo. Assim sendo, ao trabalhar com a questão patrimonial deve primeiramente observar o bem cultural para posteriormente fosse registrado por meio de fotos, desenhos, croquis, maquetes, etc. Em seguida é possível questionar o bem cultural e levantar hipóteses plausíveis para o entendimento deste e posterior apropriação do bem cultural. Em resumo, a metodologia perpassa pelos quatro passos: observar, registrar, explorar, apropriar, reforçando a ideia de 'conhecer para preservar'.

Como dito, este conceito e esta metodologia de educação patrimonial têm suas raízes na década de 1930 e nos parece não ter havido grandes mudanças até a promulgação do 'Guia de Educação Patrimonial' no final do século XX. Um dos problemas que aflora é a descontextualização da metodologia, que não absorveu as mudanças no âmbito da educação brasileira em 60 anos, dentre as quais está a relação da cultura e do mercado. A transformação da cultura em mercadoria (CANCLINI, 1999) é um fenômeno que consolidou no Brasil em meados do século XX e não pode ser desassociado da questão do patrimônio cultural.

Outro conjunto de problemas neste campo tem relação com a lógica que as instituições de cultura e de patrimônio estão atualmente submetidas: a da cultura como mercado e como negócio, na qual a meta fundamental se expressa em valores quantitativos, ou seja, público. Mais do que a qualidade do trabalho educativo ou da problematização da memória/produção do esquecimento, as instituições voltadas a este mercado da cultura, preocupadas com formação de público em volume necessário para justificar os gastos (que deveriam ser compreendidos como investimento social), tem transformado os educativos em linha de produção de conteúdos repetitivos, pouco dialogados ou criativos (SCIFONI, 2017:8).

Ou seja, a preocupação com a lógica de mercado deve ser equacionada nas ações de educação patrimonial e a simples relação 'conhecer para preservar' deve ser então complexificada. Um dos avanços neste sentido foi Instrução Normativa $n^{\circ} 001$, de 25 de março de 2015 que exige nos Licenciamentos Ambientais, um Plano Integrado de Educação Patrimonial.

$\S 1^{\circ} \mathrm{O}$ público alvo (...) será composto por comunidades impactadas pelos empreendimentos, empregados envolvidos com o empreendimento, comunidade escolar, inclusive professores das unidades selecionadas, e 
gestores de órgãos públicos localizados na $\mathrm{AID}^{7}$ do empreendimento. $\S 2^{\circ} \mathrm{A}$ equipe multidisciplinar responsável pela execução do Projeto deverá, necessariamente, contar com profissionais da área da Educação. $\S 3^{\circ} \mathrm{O}$ cronograma poderá prever ações a serem desenvolvidas também após o início de operação do empreendimento. $\S 4^{\circ}$ Atividades pontuais, tais como: palestras e ações de caráter exclusivamente promocional, assim como atividades de esclarecimento e divulgação, não são suficientes para caracterizar Projetos Integrados de Educação Patrimonial (IPHAN, 2015: § $1^{\circ}, 2^{\circ}, 3^{\circ}$ e $\left.4^{\circ}\right)$.

De acordo com a Instrução, há uma ampliação do acesso da ação de educação patrimonial bem como a necessidade de inserir profissionais qualificados da área de educação. Outro ponto de destaque é a evitar que a educação patrimonial se resume apenas em palestras e folhetos, prática essa corriqueira nas ditas ações. Não obstante a relevância do documento no âmbito da inserção da comunidade - ponto este relevante para este artigo -, esta ação só é prevista quando há um impacto de um empreendimento. Assim sendo, retomamos à ideia da 'retórica da perda' do início do IPHAN, não havendo um processo contínuo visto do ângulo das comunidades detentoras do bem cultural.

Para as comunidades, nos parece obvio que o conhecer é só vivenciado e também transmitido pelos e para os seus membros. Assim sendo, ao pensar neste binômio - 'conhecer para preservar' -, percebo que o conhecimento já ocorre bem como a preservação. No entanto, como transmitir a esta comunidade detentora do bem cultural a ideia de patrimônio cultural? Como inserir os conceitos de identidade, memória para estas? Ademais, até que ponto, a inserção destes conceitos na comunidade é importante? Retomemos a frase de Neusa de Assis Silva, Capitã do Reinado 'Os Carolinos': "se eles [as agências de preservação do Estado] colocarem as Irmandades como patrimônio e ajudar com alguma coisa, aí vai ser legal, agora se só falar esse nome, deixa do jeito que tá" (SILVA, 2017). Diante desta fala, será possível acreditar que, as atuais ações de educação patrimonial são passíveis de responder tal questão?

\section{Considerações finais}

Terminar o último tópico deste artigo com uma pergunta foi proposital e marca a necessidade de ampliarmos os debates em torno da educação patrimonial. Assim o texto permeou a questão da educação patrimonial na trajetória do IPHAN de seu início até a década

\footnotetext{
${ }^{7}$ AID = Área de Influência Direta 
de 1990. Ao longo dos tempos, o órgão preservacionista entendeu que, ao estimular o conhecimento das manifestações culturais, possibilita a promoção, a proteção e o desenvolvimento da diversidade cultural do país. Com Aloísio Magalhães, preservação ganha outro status ao afirmar que a comunidade é a melhor guardiã de seu patrimônio. No entanto, vemos que as políticas e ações de educação patrimonial se mantêm arraigadas muito mais no binômino 'conhecer para preservar', excluído os processos educacionais no âmbito das comunidades detentoras do Patrimônio Cultural. No trabalho de campo com o Reinado do Chico Calu, percebemos que o conhecimento e a preservação ocorre de maneira profícua no âmbito da Irmandade, o que falta às agencias é conseguir transmitir o discurso preservacionistas acadêmico de forma profícua.

\section{Referências}

AGENDA Mostra Benjamin de Oliveira 2016 Revista Marimbondo Irmandade Os Carolinos Disponível em: https://www.youtube.com/watch?v=s_WtkmiQvTE Acesso dia 27 de agosto de 2016.

CANCLINI, Nestor Canclini. Consumidores e cidadãos: conflitos multiculturais da globalização 4. ed. RJ, Editora UFRJ, 1999.

CAROLINOS, Os. Os Carolinos. Belo Horizonte: Canal C, 2012.

DA MATTA, Roberto. Você tem cultura? Jornal da Embratel. Rio de Janeiro: 1981.

ESCRITÓRIO INTERNACIONAL DOS MUSEUS SOCIEDADE DAS NAÇÕES. Carta de Atenas. $\quad$ Atenas: $1931 . \quad$ Disponível http://portal.iphan.gov.br/uploads/ckfinder/arquivos/Carta\%20de\%20Atenas\%201931.pdf Acesso dia 22 de setembro de 2019.

GIBRAN, Elias e MOYSÉS, Júlia. Percursos do Sagrado: Irmandades do Rosário de Belo Horizonte e entorno Belo Horizonte: Canal C - Comunicação e Cultura, 2014.

GONÇALVES, José Reginaldo Santos. A Retórica da Perda: os discursos do patrimônio cultural no Brasil. Rio de Janeiro: Editora UFRJ, 2002.

HORTA, Maria de Lourdes Parreira; GRUNBERG, Evelina; MONTEIRO, Adriane Queiroz. Guia básico de educação patrimonial. Brasília: IPHAN: Museu Imperial, 1999.

IBRAM - Instituto Brasileiro de Museus. Caderno da Política Nacional de Educação Museal. Brasília, DF: IBRAM, 2018. 
IEPHA/MG - Instituto Estadual do Patrimônio Histórico e Artístico Nacional de Minas Gerais Bens Registrados Disponível em http://www.iepha.mg.gov.br/index.php/programas-eacoes/patrimonio-cultural-protegido/bens-registrados Acesso dia 24 de setembro de 2019.

IPHAN - Instituto do Patrimônio Histórico e Artístico Nacional Carta de Fortaleza, 14 de novembro de $1997 . \quad$ Disponível em: http://portal.iphan.gov.br/uploads/ckfinder/arquivos/Carta\%20de\%20Fortaleza\%201997.pdf Acesso dia 22 de setembro de 2019.

- Educação Patrimonial: histórico, conceitos e processos Brasília: IPHAN, 2014. Disponível em http://portal.iphan.gov.br/uploads/ckfinder/arquivos/Educacao_Patrimonial.pdf Acesso dia 20 de setembro de 2019.

. Instrução Normativa N. 01, de 25 de março de 2015. Estabelece procedimentos administrativos a serem observados pelo Instituto do Patrimônio Histórico e Artístico Nacional nos processos de licenciamento ambiental dos quais participe. Diário Oficial da União, Poder Executivo, Brasília, 26 mar. 2015, sec. 1, n. 58, p. 11.

. Projetos Realizados de Identificação de Bens Culturais Imateriais. Disponível em http://portal.iphan.gov.br/pagina/detalhes/681/ Acesso dia 24 de setembro de 2019.

LOPES, João. Diferença entre reinado e congado. In: KISHIMOTO, Alexandre; TRONCARELLI, Paulo F. (orgs.). O Reinado da Reinado de Nossa Senhora do Rosário do Jatobá - Belo Horizonte/MG. São Paulo: Cachuera, 2005.

LOTT, Wanessa Pires. Patrimônio cultural na cidade de Belo Horizonte: o caso da "Irmandade de Nossa Senhora do Rosário do Jatobá" e do terreiro de candomblé "Ilê Wopo Olojukan”. Belo Horizonte: PUC Minas, 2005. (Mestrado em Gestão de Cidades).

. Tem festa de negro na República branca: o Reinado em Belo Horizonte na Primeira República. Belo Horizonte: UFMG, 2005. (Doutorado em História).

PESSÔA, J. Lúcio Costa: Documentos de trabalho. Rio de Janeiro: IPHAN. 1999.

RUBINO, Silvana. O mapa do Brasil passado. Revista do Patrimônio Histórico e Artístico Nacional, no 24, Rio de Janeiro, 1996.

SANCHIS, Pierre. Arraial: festa de um povo. As romarias portuguesas. Lisboa: Publicações Dom Quixote, 1983.

SCIFONI, Simone. Desafios para uma nova educação patrimonial. Revista Teias, vol 18, $\mathrm{n}^{\circ}$ 48, Jan-Mar, 2017.

SILVA, Neusa de Assis. Os Carolinos. Entrevista concedida em 23 de janeiro de 2017.

SIVIERO, F. Educação e patrimônio cultural: uma encruzilhada nas políticas públicas de preservação. Revista $C P C$, no 19, p. 80-108, jun. 2015. 
SOUZA, Marina de Mello e. Reis negros no Brasil escravista: história da Festa de Coroação de Rei Congo. Belo Horizonte: Editora UFMG, 2002

SPHAN e FUNDAÇÃO NACIONAL PRÓ-MEMÓRIA. Boletim 18. Brasília, Ministério da Educação e Cultura maio/junho de 1982. Disponível em http://portal.iphan.gov.br/uploads/publicacao/Boletim_18.pdf Acesso dia 23 de setembro de 2019.

Recebido em: 24/09/2019

Aprovado em: 07/03/2020 